\title{
A roadmap to explanatory pluralism: introduction to the topical collection The Biology of Behaviour
}

\author{
Eric Muszynski ${ }^{1} \cdot$ Christophe Malaterre $^{1}$
}

Published online: 22 September 2020

(c) Springer Nature B.V. 2020

\begin{abstract}
Pluralism is widely appealed to in many areas of philosophy of science, though what is meant by 'pluralism' may profoundly vary. Because explanations of behaviour have been a favoured target for pluralistic theses, the sciences of behaviour offer a rich context in which to further investigate pluralism. This is what the topical collection The Biology of Behaviour: Explanatory pluralism across the life sciences is about. In the present introduction, we briefly review major strands of pluralist theses and their motivations. We highlight three distinct types of pluralisms-type pluralism, fragmentation pluralism and insular pluralism - and introduce the articles of the topical collection.
\end{abstract}

Keywords Pluralism · Behaviour · Explanation · Integration

\section{Introduction}

The last few decades have seen a surge of publications in science and philosophy of science relating to pluralism. Authors have argued that contrary to what was defended in twentieth-century philosophy, science is not a unified endeavour, and instead calls on many theories, methods, taxonomies, ontologies, and explanatory strategies. Philosophy of biology has proven to be particularly ripe for pluralist positions, for various reasons. Some argue that the complexity of the subject matter implies that no single overarching theory will ever be sufficient to explain everything within the discipline (Mitchell 2003), others that the historical contingency of natural selection (Beatty 1993), the sheer diversity of questions being asked, or the competing scientific traditions within biology preclude any kind of unifying schemes (Morange 2015). These issues seem to be compounded in biological research relating to behaviour, where the

Christophe Malaterre

malaterre.christophe@uqam.ca

1 Département de Philosophie and Centre interuniversitaire de recherche sur la science et la technologie (CIRST), Université du Québec à Montréal (UQAM), 455 Boulevard René-Lévesque Est, Montréal, QC H3C 3P8, Canada 
complexity of the phenomena and the diversity of disciplines which can contribute to explanations give rise to much interesting research (e.g. Mitchell 2003; Laland and Brown 2011; Plaisance and Reydon 2012; Longino 2013; Tabery 2014). This makes the philosophy of behavioural biology a particularly important litmus test for pluralist positions: if pluralism does not hold in this area, then chances are that it may be difficult to defend in other areas.

Scientific pluralism can mean many different things depending on what the plurality is attributed to (Kellert, Longino, and Waters 2006a). Ontological pluralism argues that we ought to rid ourselves of the assumption that the metaphysical foundation of the world is unified. Instead, the fundamental building blocks are recognized as being multiple (Dupré 1993; Cartwright 1999; Waters 2017). This is sometimes reflected in forms of taxonomic pluralism (Dupré 1993), though an acceptance of diverse taxonomies need not imply ontological commitments (Kitcher 1984; Ereshefsky 2001). Methodological pluralism has been the object of debates, for instance as regards to the units of selection (Dawkins 1976; Sterelny and Kitcher 1988; Lloyd 1989, 2005; Sober 1990; Okasha 2006). These issues dovetail with many other forms of pluralism which are concerned with epistemic issues, such as anti-reductionist positions (Fodor 1974), as well as interactions within multi-disciplinary research domains (Longino 2002; Kellert 2008; Repko 2012). Many of these positions also relate to explanatory pluralism, which highlights the variety of explanations that science produces (Mitchell 2002; Kellert, Longino, and Waters 2006a; Mitchell 2009; Kendler 2012; Longino 2013; Ruphy 2013; Braillard and Malaterre 2015).

Explanatory pluralism has recently become the focus of much research in the philosophy of biology and behaviour. Yet despite this increased attention, it is not always entirely clear what explanatory pluralism involves, leading to some apparent confusion in the implications of such positions. For instance Gijsbers (2016) points out that whereas Campaner (2014) speaks of explanatory pluralism as emphasizing the isolation and incommensurability of different explanatory schemes, Abney and colleagues (2014) describe it as the capacity for different approaches to offer complementary and ultimately integrable explanations. Of course, both these positions could appropriately be called pluralist by different authors, but at the very least it is clear that the same term, 'explanatory pluralism', can come to mean seemingly opposite things.

This topical collection The Biology of Behaviour: Explanatory pluralism across the life sciences gathers articles written specifically about explanatory pluralism within behavioural biology. In an effort to make explicit the various explanatory pluralisms which have been proposed within philosophy of science, we first offer a roadmap which lays out the different forms of pluralism, covering three different targets we have identified which relate to the plurality of explanations. We then cover the possible motivations for such positions. We look specifically at the literature in philosophy of biology and behaviour, as this seems to be where many of these ideas are burgeoning. Finally, we introduce the articles of the topical collection. These articles offer points along our roadmap, highlighting forms of explanations, types of integration or isolation of explanations, as well as behavior research about all forms of life, from microbes to plants, to humans and other vertebrates. 


\section{Targets of explanatory pluralisms}

Those defending explanatory pluralism agree that notions regarding the unity-or eventual unification - of explanations in science are at best misguided, or worse, simply wrong. But aside from this general agreement on who the adversaries are, explanatory pluralisms can come with a wide variety of commitments and consequences.

To make sense of this multiplicity, many different typologies of pluralisms have been proposed. For example, Longino (2013, p. 147) distinguishes between eliminable and ineliminable pluralism. While the former acknowledges a current plurality of scientific explanations, it is understood to be temporary matter, with unification as the ultimate - and realistic — goal. Ineliminable pluralism, on the other hand, takes for granted that the plurality is here to stay. Mitchell (2003, pp. 186-92), for her part, proposes three different kinds of pluralisms, starting with 'anything goes pluralism,' represented by approaches such as Feyerabend's epistemological anarchism (1975, 1981). The second is 'isolationist pluralism,' which understands explanations at a given level of analysis to be impervious to explanations at other levels, as some have interpreted Mayr (1961) and Tinbergen (1963) as proposing. And third, 'integrative pluralism,' defended by Mitchell herself, which advances that certain explanation$\mathrm{s}$ - but not all — can be integrated one with the other in various ways. Van Bouwel (2014) proposes a fivefold distinction, recognizing Longino's 'eliminable pluralism' (rebranded as 'moderate pluralism'), adopting Mitchell's tripartite nomenclature, and adding another type of pluralism to this list, calling it 'interactive pluralism.' This last kind is described as a middle-of-the-road position between isolationist and integrative pluralism, which recognizes the value of interactions between explanations (or approaches) without making integration an imperative.

Though these various ways of cataloguing pluralisms have the merit of showing the nuance across positions, it can sometimes be difficult to understand precisely what it is about explanations which is plural. What does it mean for explanations to be isolated, interactive, or integrated? Are pluralists highlighting the diversity of forms, or the diversity of content within biological explanations? To shed light on these issues, we propose here to classify explanatory pluralist positions with respect to the target of pluralist claims. In other words, what it is about the explanations which is understood to be plural.

The first kind of pluralism we call 'type pluralism' applies to the types of explanations which are found in science. Defenders of this pluralism argue that scientific explanations do not—and need not—partake of a single explanatory model. Instead, sometimes even within a single discipline, different types of explanations are possible, such as explanations that appeal to covering laws, mechanistic explanations, statistical relevance explanations, causal explanations or others. It is often seen as a matter of fact that there currently exists a plurality of types of explanations in science (see for instance the articles in Kellert, Longino, and Waters 2006b; Mitchell 2002). Type pluralism for scientific explanations therefore seems to be the default stance for most contemporary philosophers of science, and as such is often left undefended, at least in any explicit form (though some are interested in fine-grained distinctions between types; see e.g. Issad and Malaterre 2015; Aizawa and Gillett 2019). Yet as Plutynski 
(2016) points out, even in this narrow application of type pluralism, many positions can be espoused, such as defending a diversity of representations, a diversity of questions, or a diversity of "modes" of explanation. These various positions are often advanced without explicit recognition of their differences. The target of this kind of pluralism is thus the type of explanations that are possible in science.

The second kind of pluralism is 'fragmentation pluralism,' and defends the idea that explanations will never merge into a grand, unified explanation or theory of everything. Sandra Mitchell is currently the most well-known philosopher of science to defend such an approach. In her view, it is sometimes possible to combine or coordinate explanations for a particular phenomenon through specific integrative strategies, but not in every case. For instance, some explanations will resist reduction from one level to another (Mitchell 2003, p. 186; 2009, chap. 2), and others, even within a single level, will not converge because they "only describe what would happen in non-overlapping ideal worlds" (Mitchell 2003, p. 64). Opportunities for integration arise in particular, concrete, non-idealized cases, where a specific phenomenon can be explained using diverse approaches. As Mitchell states: "However complex, and however many contributing causes participated, there is only one causal history that, in fact, has generated a phenomenon to be explained" (Mitchell 2002, p. 65). That single particular causal history is understood to be amenable to only one complete explanation, which may call on the integration of various models. However, though there may be opportunities for integration in particular cases and therefore little chance for pluralism at that level, the abstracted, generalized, broad, unified explanations will forever be out of reach (Mitchell and Dietrich 2006). Thus, what is plural for this kind of pluralism is the general, abstract, or theoretical level of explanations, the contention being that no explanation will ever be large enough to contain all the particular phenomena to be explained by science; as such, science will remain fragmented.

The third and final form of pluralism is 'insular pluralism' and is in many respects the most forceful application of explanatory pluralist ideas. This is the view that two (or more) different scientific approaches may explain a given phenomenon in ways which are not only different, but impossible to integrate or even compare. This is furthermore not seen as a problem in need of resolution but instead as the result of science running its course (Kellert, Longino, and Waters 2006b). Longino (2013) defends this form of pluralism in behavioural biology, arguing that different approaches will parse the causal space implicated in a given behaviour in different ways, sometimes leading to incompatible explanations. Furthermore, the resulting explanations may not be in a position to invalidate the others (see also Waters 2005). Longino argues that this is the case because the success of a scientific explanation is not evaluated in terms of truth or falsity, but rather "conformation" (a notion introduced in Longino 2002). Conformation encompasses "truth (literal) at one extreme, but also isomorphism, homomorphism, similarity, approximation, and other relations that name forms of success in representation" (Longino 2013, pp. 147-48). By removing the binary of truth and falsity, explanations are no longer understood to be the whole story about a given phenomenon, but only a more or less successful representation thereof. Moreover, because the measure of conformation itself is done only within the context of each discipline, cross-discipline comparisons of levels of conformation are, at least 
sometimes, impossible. Explanations can therefore be incommensurable, precluding the integration of explanations for a given phenomenon, implying that there exists a plurality of explanations which is here to stay. In sum, insular pluralism targets the content of the explanations, positing that there can exist a plurality of contents of explanations which, even if they are incompatible, is not problematic.

This typology of pluralisms, distinguishing type pluralism, fragmentation pluralism and insular pluralism, captures divisions which were not covered by those previously proposed. Consider Longino's (2013) two-way distinction between eliminable and ineliminable pluralisms: each of the kinds of pluralism we here laid out can be of either sort. For instance, one could either defend that the variety of types of explanations could one day be subsumed under a single type, hence be eliminable, or that type pluralism is permanent, hence ineliminable. Insular pluralism seems constrained to be of the ineliminable sort, though one could imagine a future state of science where extensive interdisciplinary work could break down at least some of the incommensurability between approaches. Nevertheless, one may still argue that this would never eliminate all explanatory pluralism. As for fragmentation pluralism, it explicitly endorses ineliminable pluralism at the more abstract level but endorses some form of eliminable pluralism more locally. Considering the distinctions proposed by Mitchell and extended by Van Bouwel—anything goes pluralism, isolationist pluralism, integrative pluralism, as well as moderate pluralism and interactive pluralism-some could be interpreted as applying to explanations at a broad, theoretical scale (hence a form of fragmentation pluralism), or explanations applied to specific, concrete phenomena (and in that case related to insular pluralism). It is also interesting to note that the concept of levels of analysis present in Mitchell's 'isolationist pluralism' could be put forward to argue for forms of fragmentation pluralism or forms of insular pluralism. Finally, none of the previously proposed pluralisms easily apply to types of explanations, reinforcing the idea that type pluralism is the default stance for philosophers of science.

\section{Motivations for pluralism}

Many different arguments are marshalled in favour of pluralist positions in philosophy of science and can be classified into three broad categories. The first are the pragmatic arguments, which generally concern resource allocation for research and the promotion of a diversity of perspectives (e.g. Kitcher 1990; Dupré 2002; Mitchell 2009). Pluralism is here seen as a way to hedge bets against monist stances which would encourage only one, or a select few, disciplines or research agendas considered to be the 'right' way of going about making scientific discoveries (Kellert, Longino, and Waters 2006b, xxi). Instead, it is argued, we ought to encourage a wide variety of approaches, and ideally finance many different research groups, in order to maximize the number of perspectives as relates to a given research question.

The pragmatic motivations obviously dovetail with some of the epistemic considerations in favour of explanatory pluralism. This is the case, for instance, with new trends in epistemology and philosophy of science, as seen in the 'values in science' debate (e.g., Elliott and Steel 2017), which emphasize the fact that science is practiced within 
a social context. This implies that both the production and the evaluation of scientific knowledge are inextricably linked to values other than those traditionally attributed to objective knowledge about the world (e.g. Longino 1990, 2002; Dupré 2007; Douglas 2007, 2009). These arguments are frequently informed by feminist approaches which are critical of mainstream science (e.g. Wylie 2003; Crasnow 2013), and often highlight the potentially damaging aspects of the pursuit of 'objective truth', such as the discrimination or silencing of minorities. In sum, since the pursuit of traditional 'objective truth' is regarded as an impossible and sometimes harmful objective, it is best to recognize that contributions to scientific knowledge can come from many different sources, opening the door to different forms of pluralism.

Another epistemic motivation for pluralism comes from the exploration of the limitations of any given scientific explanation. By virtue of being representations, explanations of a phenomenon will by definition be partial, implying that no single explanation will suffice for a complete explanation (Mitchell 2009 chap. 2; Longino 2013, p.147). Giere (2006) compares this situation with that of colour vision: visual systems can differ in humans and other species, with no way of determining which is the 'correct' way of perceiving colour-though some can be richer than others. In much the same way, scientific explanations only ever give us a part of the complete explanation. Horst's (2016) cognitive pluralism extends this approach by showing the various ways cognitive mechanisms shape our parsing of the world. Explanatory pluralism can thus be defended on epistemic grounds without appeal to social factors, by instead emphasizing the limitations inherent to our ways of apprehending the world, and the resulting representations of that understanding through scientific explanations.

Finally, some will tie in motivations relating to ontological pluralism. This is the case for instance with Dupré's (1993) "promiscuous realism" which advances that the multiple, even conflicting, classificatory practices used to further human interests are all real and referential. This multiplicity is in turn reflected in the resulting scientific explanations, which entails that the metaphysical foundations of the world are similarly disunified. Nancy Cartwright (1999) has also defended a metaphysical view of a "dappled world", which is composed of different realms, restricting the scope of explanations, thus precluding unification. In a similar vein, Waters (2017) argues that current biological practice reflects the fact that there is "no general structure" in the world's underlying framework; instead, its messiness is reflected in the piecemeal descriptions and explanations put forth by (for instance) geneticists. Ontological pluralism can thus be seen as the reason for different kinds of explanatory pluralism and is therefore often revealed through the explanatory practices of practicing scientists.

Of course, within these three broad categories of motivations for explanatory pluralism are countless arguments and strategies. Some will begin with specific case studies, others with broad considerations regarding science in general, others still with a look at science in practice. There is thus a wide range of types of arguments and nuances which can be brought forth in favour of explanatory pluralisms. 


\section{Contributions to the topical collection}

Explaining behaviour has turned out to be a very fertile ground for developing and probing various theses about scientific pluralism (e.g., Mitchell 2003; Longino 2013). Behaviour is evidently attributable to humans, but many other biological entities can also be said to exhibit behaviour. At a workshop we organized in 2018 in Montreal, behaviour and pluralism were discussed at many different levels of biological organization, from plants and mollusks up to humans and collectives. Whereas behaviour tends to be attributed to organisms that have neuronal systems, the study of plants has recently uncovered ways in which "brainless organisms" may indeed display peculiar forms of behaviours when interacting with their environment, including other plants (Cahill 2019), thereby raising the question whether one or several concepts of behaviour are needed to capture the range of natural phenomena usually labeled "behaviour." Interestingly also, the study of organisms that have some of the simplest neuronal systems now tends to show that behaviour can be understood in extremely detailed ways, even at the level of specific molecular inducers (Farah et al. 2017), providing a possible glimpse into reductive explanations of behaviour. Phenomena of collective behaviour and social learning, such as with certain species of caterpillars or fishes (Despland and Santacruz Endara 2016; Cabrera-Álvarez, Swaney, and Reader 2017) also provide challenging perspectives on how to model and explain behaviour at the level of groups of organisms, and whether certain forms of explanatory pluralism might obtain in such controlled experimental settings. At the more complex end of the scale, human behaviour is the object of much inquiry, leading to pluralist debates about, for instance, the limited explanatory role of genetics with regards to behaviour, the possible importance of epigenetics or the role played by the social context (Matthews and Turkheimer 2019; Poirier and Faucher 2020). Such specific cases of behaviour and the way they are characterized by science today make it possible to revisit more conceptual questions, such as whether Tinbergen's four major categories for explanations of animal behavior-mechanism, adaptive value, ontogeny, and phylogeny — can be considered as four independent categories or not (Laland et al. 2013), which role developmental factors have in explaining behavior (Wey, Réale, and Kelly 2019), or whether behaviour requires other specific types of explanations such as intentional explanations (Bekoff and Allen 1995). More general questions are also raised, such as what our ontological commitments can tell us about the possibility of pluralism (Hochstein 2019), or how we might envision integration (Brigandt 2010). The ubiquity of behaviour at all levels of biological organisation also raises questions about whether we are dealing with disunity regarding the very concept of behaviour (Levitis, Lidicker, and Freund 2009; Longino 2013), or whether these different conceptualisations of behaviour can be construed as gradations which point to a more unified class of phenomena (Muszynski and Malaterre 2019).

The topical collection The Biology of Behaviour: Explanatory pluralism across the life sciences includes articles authored by several of the Montreal workshop participants, as well as independent submissions that offer perspectives on the many facets of pluralism in explanations of behavior, from plants to humans.

Quentin Hiernaux's contribution "History and epistemology of plant behaviour: a pluralistic view?" focuses on plant behaviour (Hiernaux 2019). The very use of the term 
'behaviour' applied to plants can be seen as contentious by some plant biologists, who explain the reactions of plants to their environment through reductive physiological mechanisms. However, others are now pushing for a recognition that plant behaviour can also, or sometimes, be explained by appeal to decisions, intentions, and even consciousness. Hiernaux shows that these two camps actually have long been opposed in the history of botany, and have led to differing methodological approaches. This lack of methodological unity opens the door to the three different kinds of pluralisms laid out above, though Hiernaux points out that their incompatibility is not a given.

In their contribution "Explaining the behaviour of random ecological networks: the stability of the microbiome as a case of integrative pluralism", Roger Deulofeu, Javier Suárez and Alberto Pérez-Cervera focus on explanations of ecological systems that include microbial organisms (Deulofeu, Suárez, and Pérez-Cervera 2019). Their research shows how issues relating to type pluralism can have repercussions on fragmentation or insular pluralism. While the debate is ongoing as to whether ecosystems can be explained through either mechanistic or mathematical explanations, Delofeu et al. show that specific types of ecosystems - those that organize forming random networks - draw their explanatory power from a combination of both types of explanation. Using the example of the human microbiome, they make a case for integrative pluralism, arguing that a satisfactory explanation is achieved only through a combination of both mechanistic and mathematical approaches.

In his "Whales, fish and Alaskan bears: interest-relative taxonomy and kind pluralism in biology", Henry Taylor proposes to target cases of taxonomical pluralism that arise, among others, from an interplay between behaviour and other characteristics of species (Taylor 2019). Interest-relative biological taxonomy approaches propose that biological categories arise from the interests of the researchers looking into particular phenomena or species. A common criticism they face is that taxonomies may end up being as disparate as the sum of interests of each individual researcher. Taylor argues for stringent criterion which allow for taxonomic systems to be rejected if they fail to be the best available taxonomy for fulfilling the purpose related to the relevant interest. His approach shows how taxonomic practices interplay with explanatory objectives as well as non-scientific interests, resulting in a plurality of categorisations.

Targeting human behaviour, Lucas J. Matthews and Eric Turkheimer focus on genetic explanations of complex human behaviour as a test case for pluralism in their contribution entitled "Across the great divide: pluralism and the hunt for missing heritability" (Matthews and Turkheimer 2019). Human behavioural genetic studies evaluate the heritability of behavioural traits through twin and adoption studies, whereas molecular genetic studies attempt to find specific loci in our genes which could account for behaviours. The "Missing Heritability Problem" is the fact that behavioural genetics consistently shows higher heritability for all traits than can be found in even the most sophisticated and extensive molecular genetic studies. Matthews and Turkheimer argue that this problem is theoretically ineliminable because of the causal incommensurability of the different approaches (a form of insular pluralism), as well as being practically ineliminable because of the ethical constraints on experiments conducted on humans.

Explanatory pluralism can also be a matter of uncovering and characterizing sources of variability among behaviour-triggering cognitive capabilities. This is what Pierre 
Poirier and Luc Faucher investigate in their contribution "A New Hope: A better ICM to understand human cognitive architectural variability" (Poirier and Faucher 2020). An Integrative Causal Model (ICM) is understood as a general framework for facilitating integration of explanations across various fields. Using research from cognitive network neuroscience, enactive cognition, and developmental systems theory, Poirier and Faucher propose to replace evolutionary psychology's ICM, which underpins many essentialist theories of cognition. They show how their new model can be applied to research on gendered cognition, demonstrating a form of fragmentation pluralism, and the resulting local integration of models and explanations.

Finally, in "Scaling up; scaling down: What's missing?" Helen E. Longino focuses on human behaviour and the different ways it can be conceptualized (Longino 2019). Building on previous work (Longino 2013), she argues that the pluralism she highlighted in the biology of human behaviour is not limited to the explanations themselves, but to the conceptualization of the object of inquiry as well. Whereas behaviour is typically understood as an individual action resulting from individual dispositions, or sometimes as the result of properties of groups, Longino adds a third option: behaviour as an interaction. Recognizing that the behaviour of individuals is fundamentally relational, she proposes that the interactions between individuals or groups could become an ontological object of investigation, regardless of the individuals involved. With such an approach, we could for instance investigate the frequency or change of certain interactions in populations. This novel conceptualization of behaviour has interesting consequences with respect to classifications of behaviours and opens avenues for new types of explanations of behaviour.

\section{The road ahead}

These contributions give us points in the landscape offered by the various forms of type pluralism, fragmentation pluralism, and insular pluralism. Yet even within the relatively narrow domain of pluralism in the biology of behaviour, these articles cover only a small subset of the relevant levels of organisation and types of organisms, and a small portion of the possible perspectives or kinds of pluralisms which can be defended. Further avenues of research are abundant. For instance, as mentioned earlier, little work is done on type pluralism, though the details and consequences of such a position would merit being fleshed out. Adherents to fragmentation pluralism or insular pluralism may also contribute to the literature by outlining precisely the impediments to unification or integration (as do, e.g. Longino 2013; Matthews and Turkheimer 2019), and the relation of explanations qua representations to the world-or even if this relation is that sought by scientific explanations (as do, e.g. Giere 2006; Mitchell 2009; Longino 2002).

One recurring yet often poorly defined concept in debates regarding pluralism is the notion of 'integration.' This is roughly the idea that explanations can, in one way or another, merge to provide a more complete or more apt explanation of a phenomenon. Though many seem to agree that integration is valuable, little has been said to justify its value, nor to describe precisely what integration amounts to, despite the fact that many (sometimes piecemeal) accounts exist (see e.g. Darden and Maull 1977; Kitcher 
1981; Brigandt 2013; Leonelli 2013; O’Malley 2013; Hochstein 2017; Sullivan 2017; Laubichler, Prohaska, and Stadler 2018). An account which could comprehensively circumscribe what is integration, how it is done, and why it ought to be pursued (or not) would be a valuable addition to the current state of research.

A final lingering question we would like to raise is whether pluralist stances ought to be understood as assertions about the future of science, or whether they are to be understood as (mere?) descriptions of the present state of science. The answer to this question could have implications regarding the relation of pluralism to the methods of science, as well as its aims.

Acknowledgements The authors thank the audience of the conference "The Biology of Behaviour: Explanatory Pluralism Across the Life Sciences" where the initial idea of this topical collection emerged (UQAM, Montréal, May 10-11th, 2018). We thank Wiebe van der Hoek, our editor-in-chief at Synthese, for his trust and assistance, as well as the numerous reviewers we mobilized for the submissions we received for this topical collection (as per Synthese rule, all submissions have been double-blind reviewed). We also thank Anne-Marie Gagné-Julien, Denis Réale and Helen Longino. EM acknowledges funding from Canada Social Sciences and Humanities Research Council [Award 767-2014-1224]. CM acknowledges funding from Canada Social Sciences and Humanities Research Council [Grant 430-2018-00899] and from Canada Research Chair in Philosophy of the Life Sciences at UQAM [CRC-950-230795].

\section{References}

Abney, D. H., Dale, R., Yoshimi, J., Kello, C. T., Tylén, Kristian, \& Fusaroli, R. (2014). Joint perceptual decision-making: a case study in explanatory pluralism. Frontiers in Psychology. https://doi.org/10.3 389/fpsyg.2014.00330.

Aizawa, K., \& Gillett, C. (2019). Defending pluralism about compositional explanations. Studies in History and Philosophy of Science Part C: Studies in History and Philosophy of Biological and Biomedical Sciences, 78, 101202. https://doi.org/10.1016/j.shpsc.2019.101202.

Beatty, J. (1993). The evolutionary contingency thesis. In G. Wolters \& J. G. Lennox (Eds.), Concepts, theories, and rationality in the biological sciences (pp. 45-81). Pittsburgh: University of Pittsburgh Press.

Bekoff, M., \& Allen, C. (1995). Teleology, function, design and the evolution of animal behaviour. Trends in Ecology \& Evolution, 10(6), 253-255. https://doi.org/10.1016/S0169-5347(00)89082-5.

Braillard, P.-A. \& Malaterre, C. (2015). Explanation in biology: An introduction. In P.-A. Braillard \& C. Malaterre (Eds.), Explanation in biology (pp. 1-28). Dordrecht: Springer. https://doi.org/10.1007/97 8-94-017-9822-8.

Brigandt, I. (2010). Beyond reduction and pluralism: Toward an epistemology of explanatory integration in biology. Erkenntnis, 73(3), 295-311.

Brigandt, I. (2013). Integration in biology: Philosophical perspectives on the dynamics of interdisciplinarity. Studies in History and Philosophy of Science Part C: Studies in History and Philosophy of Biological and Biomedical Sciences, 44(4), 461-465. https://doi.org/10.1016/j.shpsc.2013.09.009.

Cabrera-Álvarez, M. J., Swaney, W. T., \& Reader, S. M. (2017). Forebrain activation during social exposure in wild-type guppies. Physiology \& Behavior, 182(December), 107-113. https://doi.org/10.1016/j. physbeh.2017.10.012.

Cahill, J. F. (2019). The inevitability of plant behavior. American Journal of Botany, 106(7), 903-905.

Campaner, R. (2014). Explanatory pluralism in psychiatry: What are we pluralists about, and why? In M. C. Galavotti, D. Dieks, W. J. Gonzalez, S. Hartmann, T. Uebel, \& M. Weber (Eds.), New directions in the philosophy of science (pp. 87-104). Dordrecht: Springer. https://doi.org/10.1007/978-3-319-0438 $2-1$.

Cartwright, N. (1999). The dappled world: A study of the boundaries of science. Cambridge: Cambridge University Press.

Crasnow, S. (2013). Feminist philosophy of science: Values and objectivity. Philosophy Compass, 8(4), $413-423$. 
Darden, L., \& Maull, N. (1977). Interfield theories. Philosophy of Science, 44(1), 43-64. https://doi.org/1 $0.1086 / 288723$.

Dawkins, R. (1976). The Selfish Gene. Oxford: Oxford University Press.

Despland, E., \& Endara, P. S. (2016). Silk drives aggregation and following in the neotropical caterpillar Mechanitis Menapis (Nymphalidae: Ithomiini). Physiological Entomology, 41(3), 274-280.

Deulofeu, R., Suárez, J., \& Pérez-Cervera, A. (2019). Explaining the behaviour of random ecological networks: The stability of the microbiome as a case of integrative pluralism. Synthese. https://doi.org/ 10.1007/s11229-019-02187-9.

Douglas, H. E. (2009). Science, policy, and the value-free ideal. Pittsburgh, PA: University of Pittsburgh Press.

Douglas, H. E. (2007). Rejecting the ideal of value-free science. In H. Kincaid, A. Wylie, \& J. Dupré (Eds.), Value-free science? Ideals and illusions (pp. 120-41). Oxford: Oxford University Press.

Dupré, J. (1993). The disorder of things: Metaphysical foundations of the disunity of science. Cambridge: Harvard University Press.

Dupré, J. (2002). The lure of the simplistic. Philosophy of Science, 69(S3), S284-S293. https://doi.org/10. $1086 / 341852$.

Elliott, K. C., \& Steel, D. (Eds.). (2017). Current controversies in values and science. Current Controversies in Philosophy. New York: Routledge, Taylor \& Francis Group.

Ereshefsky, M. (2001). The poverty of the linnaean hierarchy: A philosophical study of biological taxonomy. Cambridge: Cambridge University Press.

Farah, C. A., Hastings, M. H., Dunn, T. W., Gong, K., Baker-Andresen, D., \& Sossin, W. S. (2017). A PKM generated by calpain cleavage of a classical PKC is required for activity-dependent intermediate-term facilitation in the presynaptic sensory neuron of Aplysia. Learning \& Memory, 24(1), 1-13. https:// doi.org/10.1101/lm.043745.116.

Feyerabend, P. (1975). Against method: Outline of an anarchistic theory of knowledge. Atlantic Highlands: NLB: Humanities Press.

Feyerabend, P. (1981). Philosophical papers. Cambridge: Cambridge University Press.

Fodor, J. A. (1974). Special sciences: Or the disunity of science as a working hypothesis. Synthese, 28, $97-115$.

Giere, R. N. (2006). Perspectival pluralism. In S. H. Kellert, H. E. Longino, \& C. K. Waters (Eds.), Scientific pluralism (pp. 26-41). Minnesota Studies in the Philosophy of Science. Minneapolis, MN: University of Minnesota Press.

Gijsbers, V. (2016). Explanatory pluralism and the (dis)unity of science: the argument from incompatible counterfactual consequences. Frontiers in Psychiatry. https://doi.org/10.3389/fpsyt.2016.00032.

Hiernaux, Q. (2019). History and epistemology of plant behaviour: A pluralistic view? Synthese. https:// doi.org/10.1007/s11229-019-02303-9.

Hochstein, E. (2019). How metaphysical commitments shape the study of psychological mechanisms. Theory \& Psychology, 29(5), 579-600. https://doi.org/10.1177/0959354319860591.

Hochstein, E. (2017). Why one model is never enough: A defense of explanatory holism. Biology \& Philosophy, 32(6), 1105-1125.

Horst, S. W. (2016). Cognitive pluralism. Cambridge, MA: MIT Press.

Issad, T., \& Malaterre, C. (2015). Are dynamic mechanistic explanations still mechanistic? In P.-A. Braillard \& C. Malaterre (Eds.), Explanation in biology. An enquiry into the diversity of explanatory patterns in the life sciences (pp. 265-292). Dordrecht: Springer.

John, D. (2007). Fact and value. In H. Kincaid, J. Dupré, \& A. Wylie (Eds.), Value-free science? Ideals and illusions (pp. 27-41). Oxford: Oxford University Press.

Kellert, S. H. (2008). Borrowed knowledge: Chaos theory and the challenge of learning across disciplines. Chicago: University of Chicago Press.

Kellert, S. H., Longino, H. E. \& Waters, C. K., Eds. (2006a). Scientific pluralism. Minnesota Studies in the Philosophy of Science (vol. 19). Minneapolis, MN: University of Minnesota Press.

Kellert, S. H., Longino, H. E. \& Waters, C. K., Eds. (2006b). The pluralist stance. In S. H. Kellert, H. E. Longino, \& C. K. Waters (Eds.), Scientific pluralism. Minnesota Studies in the Philosophy of Science. (vol. 19, pp. vii-xxix). Minneapolis, MN: University of Minnesota Press.

Kendler, K. S. (2012). The dappled nature of causes of psychiatric illness: Replacing the organic-functional/hardware-software dichotomy with empirically based pluralism. Molecular Psychiatry, 17(4), 377-388. https://doi.org/10.1038/mp.2011.182.

Kitcher, P. (1981). Explanatory unification. Philosophy of Science, 48(4), 507-531. 
Kitcher, P. (1984). Species. Philosophy of Science, 51(2), 308-333.

Kitcher, P. (1990). The division of cognitive labor. The Journal of Philosophy, 87(1), 5. https://doi.org/10. $2307 / 2026796$.

Laland, K. N., \& Brown, G. R. (2011). Sense and nonsense: Evolutionary perspectives on human behaviour (2nd ed.). New York: Oxford University Press.

Laland, K. N., Odling-Smee, J., Hoppitt, W., \& Uller, T. (2013). More on how and why: Cause and effect in biology revisited. Biology and Philosophy, 28(5), 719-745. https://doi.org/10.1007/s10539-012-9 335-1.

Laubichler, M. D., Prohaska, S. J., \& Stadler, P. F. (2018). Toward a mechanistic explanation of phenotypic evolution: The need for a theory of theory integration. Journal of Experimental Zoology Part B: Molecular and Developmental Evolution, 330(1), 5-14. https://doi.org/10.1002/jez.b.22785.

Leonelli, S. (2013). Integrating data to acquire new knowledge: Three modes of integration in plant science. Studies in History and Philosophy of Science Part C: Studies in History and Philosophy of Biological and Biomedical Sciences, 44(4), 503-514. https://doi.org/10.1016/j.shpsc.2013.03.020.

Levitis, D. A., Lidicker, W. Z., \& Freund, G. (2009). Behavioural biologists do not agree on what constitutes behaviour. Animal Behaviour, 78(1), 103-110. https://doi.org/10.1016/j.anbehav.2009.03.018.

Lloyd, E. A. (1989). A structural approach to defining units of selection. Philosophy of Science, 56(3), 395-418. https://doi.org/10.1086/289498.

Lloyd, E. A. (2005). Why the gene will not return. Philosophy of Science, 72(2), 287-310. https://doi.org/ $10.1086 / 432425$.

Longino, H. E. (1990). Science as social knowledge. Princeton: Princeton University Press.

Longino, H. E. (2002). The fate of knowledge. Princeton: Princeton University Press.

Longino, H. E. (2013). Studying human behaviour: How scientists investigate aggression and sexuality. Chicago: University of Chicago Press.

Longino, H. E. (2019). Scaling up; scaling down: What's missing? Synthese. https://doi.org/10.1007/s112 29-019-02249-y.

Matthews, L. J., \& Turkheimer, E. (2019). Across the great divide: Pluralism and the hunt for missing heritability. Synthese. https://doi.org/10.1007/s11229-019-02205-w.

Mayr, E. (1961). Cause and effect in biology. Science, 134(3489), 1501-1506. https://doi.org/10.1126/ science.134.3489.1501.

Mitchell, S. D. (2002). Integrative pluralism. Biology and Philosophy, 17(1), 55-70.

Mitchell, S. D. (2003). Biological complexity and integrative pluralism. Cambridge Studies in Philosophy and Biology. Cambridge, MA: Cambridge University Press.

Mitchell, S. D. (2009). Unsimple truths: Science, complexity, and policy. Chicago: University of Chicago Press.

Mitchell, S. D., \& Dietrich, M. R. (2006). Integration without unification: An argument for pluralism in the biological sciences. The American Naturalist, 168(S6), S73-S79. https://doi.org/10.1086/509050.

Morange, M. (2015). Is there an explanation for...the diversity of explanations in biological studies? In P.-A. Braillard \& C. Malaterre (Eds.), Explanation in biology. Dordrecht: Springer. https://doi.org/1 0.1007/978-94-017-9822-8.

Muszynski, E., \& Malaterre, C. (2019). Best behaviour: A proposal for a non-binary conceptualization of behaviour in biology. Studies in History and Philosophy of Science Part C: Studies in History and Philosophy of Biological and Biomedical Sciences. https://doi.org/10.1016/j.shpsc.2019.101222.

O'Malley, M. A. (2013). When integration fails: Prokaryote phylogeny and the tree of life. Studies in History and Philosophy of Science Part C: Studies in History and Philosophy of Biological and Biomedical Sciences, 44(4), 551-562. https://doi.org/10.1016/j.shpsc.2012.10.003.

Okasha, S. 2006. Evolution and the levels of selection. Oxford : Oxford University Press.

Plaisance, K. S., \& Reydon, T. A. C. (Eds). (2012). Philosophy of behavioral biology (vol. 282). Boston Studies in the Philosophy of Science. Dordrecht: Springer.

Plutynski, A. (2016). Explanatory pluralism in the life sciences. Science \& Education 25(5-6), 681-689. https://doi.org/10.1007/s11191-016-9843-5.

Poirier, P., \& Faucher, L. (2020). A new hope: A better ICM to understand human cognitive architectural variability. Synthese. https://doi.org/10.1007/s11229-020-02739-4.

Repko, A. F. (2012). Interdisciplinary research: Process and theory (2nd ed.). Thousand Oaks, Calif: SAGE Publications.

Ruphy, S. (2013). Pluralismes scientifiques: Enjeux épistémiques et métaphysiques. Paris: Hermann. 
Sober, E. (1990). The poverty of pluralism: A reply to sterelny and kitcher. The Journal of Philosophy, 87(3), 151. https://doi.org/10.2307/2026633.

Sterelny, K., \& Kitcher, P. (1988). The return of the gene. The Journal of Philosophy, 85(7), 339. https:// doi.org/10.2307/2026953.

Sullivan, J. A. (2017). Coordinated pluralism as a means to facilitate integrative taxonomies of cognition. Philosophical Explorations, 20(2), 129-145.

Tabery, J. (2014). Beyond versus: The struggle to understand the interaction of nature and nurture. Life and Mind: Philosophical Issues in Biology and Psychology. Cambridge, Massachusetts: MIT Press.

Taylor, H. (2019). Whales, fish and alaskan bears: Interest-relative taxonomy and kind pluralism in biology. Synthese. https://doi.org/10.1007/s11229-019-02284-9.

Tinbergen, N. (1963). On aims and methods of ethology. Animal Biology, 55(4), 297-321.

Van Bouwel, J. (2014). Pluralists about pluralism? Different versions of explanatory pluralism in psychiatry. In M. C. Galavotti, D. Dieks, W. J. Gonzalez, S. Hartmann, T. Uebel, \& M. Weber (Eds.), New directions in the philosophy of science (pp. 105-120). Dordrecht: Springer. https://doi.org/10.1007/978-3-319-0 $4382-1$.

Waters, C. K. (2005). Why genic and multilevel selection theories are here to stay. Philosophy of Science, 72(2), 311-333. https://doi.org/10.1086/432426.

Waters, C. K. (2017). No general structure. In M. Slater \& Z. Yudell (Eds.), Metaphysics and the philosophy of science (pp. 81-108). Oxford: Oxford University Press. https://doi.org/10.1093/acprof:oso/978019 9363209.003.0005.

Wey, T. W., Réale, D., \& Kelly, C. D. (2019). Developmental and genetic effects on behavioral and lifehistory traits in a field cricket. Ecology and Evolution, 9(6), 3434-3445.

Wylie, A. (2003). Why standpoint theory matters. In R. Figueroa \& S. G. Harding (Eds.), Science and other cultures: Issues in philosophies of science and technology. New York: Routledge.

Publisher's Note Springer Nature remains neutral with regard to jurisdictional claims in published maps and institutional affiliations. 